\title{
O mal (estar) da juventude
}

\section{Sebastiana Fadda}

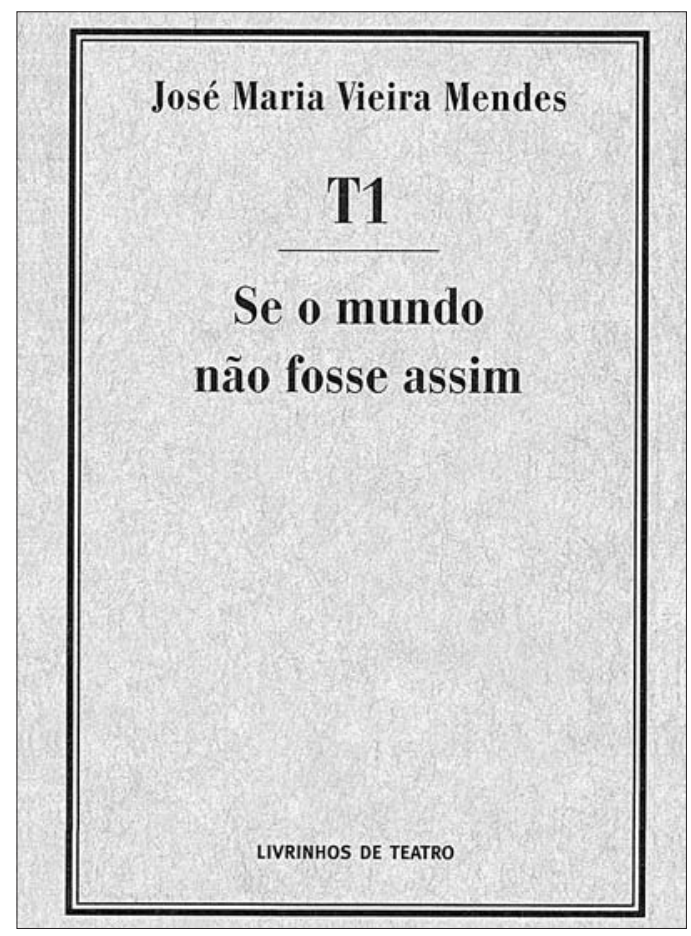

0 nome de José Maria Vieira Mendes pode ser inserido sem hesitações na lista dos mais jovens e talentosos autores teatrais portugueses contemporâneos. Estreou-se, porém, como dramaturgista, mostrando desde logo uma habilidade que o impôs à atenção da crítica e the valeu 0 reconhecimento institucional pela atribuição, num mesmo ano, dos prestigiados Prémio Revelação Ribeiro da Fonte 2000 para teatro (promovido pelo então Instituto Português das Artes do Espectáculo, hoje Instituto das Artes) e Prémio Acarte - Maria Madalena de Azeredo Perdigão 2000 (atribuido pela Fundação Calouste Gulbenkian, no âmbito do entretanto extinto serviço Acarte).

No insólito de situações à beira da insanidade mental ou do crime, da tolerabilidade psicológica ou emotiva, mergulham os protagonistas de Dois homens (1998), Crime e castigo (1999) e Morrer (1999), baseadas respectivamente em narrativas de Kafka, Dostoievski e Schnitzler. Nas três adaptações ao palco evidencia-se o sentido da economia da palavra e do enredo, bem como uma sensibilidade atenta ao ritmo da linguagem verbal e teatral. Contudo, a preocupação formal que leva o autor a dedicar cuidados especiais à sonoridade e ao lirismo da palavra enquanto instrumento artístico, não se traduz em mera autocomplacência estética. Pressente-se, nítida, também a preocupação intelectual de transmitir significados que não

\author{
José Maria Vieira Mendes, T1 / Se o mundo \\ não fosse assim, Lisboa, Artistas Unidos, \\ Colecção Livrinhos de Teatro, 2004, 120 pp.
}

sejam óbvios, mas antes matéria incandescente que corre em várias direcções referenciais. De tal modo que a formação, o rigor e a meticulosidade exigentes do autor se reflectem nos resultados finais das suas criações: pequenos mecanismos que anseiam pelo perfeito equilibrio entre elementos igualmente fundamentais como literatura, tensão emotiva, teatralidade e lirismo.

Vejam-se mais em pormenor essas três experiências, a fim de destrinçar a forte incidência do trabalho do dramaturgista na criação posterior do dramaturgo.

Dois homens, redigido por um José Maria Vieira Mendes mais maduro do que os vinte e dois anos que tinha na altura, é um monólogo baseado na fusão de vários textos de Franz Kafka. 0 protagonista é um funcionário, um burocrata como o anti-herói de A metamorfose. 0 escritório onde se movimenta é ao mesmo tempo a sua prisão e a sua toca. Vitima e carrasco dos acontecimentos da sua vida, ele é culpado por existir, escravo da sua própria mente, de fantasias e pensamentos obsessivos. A sociedade em sentido lato, mas sobretudo os membros da sua família e o pai em particular, são acusados de o terem defraudado dos direitos primários, de amor, protecção e segurança. Vazios interiores que soltam um grito doloroso, libertador de medos antigos, de loucuras ocultadas, do medo da loucura. A ambivalência dos sentimentos - por um lado, a rejeição do cativeiro e, por outro, o terror da liberdade - são apenas manifestações da incapacidade de adaptação a regras e expectativas alienantes. Ou seja: a sociedade organizada é fonte de alienação; a autonomia, faltando os instrumentos idóneos para o seu exercício, é causa de dissolução do "eu". 0 universo kafkiano encontra-se reproduzido com fidelidade impressionante, os monstros que o povoam revivem nas evocações dum artista inadaptado ao social, devorado por pesadelos e fantasmas alimentados por figuras de referência autoritárias e castradoras.

Crime e castigo deu origem a um espectáculo multimédia e interdisciplinar, com música rock ao vivo e o uso do vídeo como complemento. Os vários enredos traçados no romance emaranharam-se no palco, numa pluralidade de vozes e tons para caracterizar as diferentes e numerosas personagens. A recriação evocativa e sugestiva foi preferida à explicitação gestual e verbal. 0 espectáculo não pretendeu ser ilustrativo, nem os actores se identificavam com as personagens. A sugestão, o excesso e a transfiguração eram por vezes os frágeis pontos de força escolhidos para transmitir as contradições da alma humana, observadas 


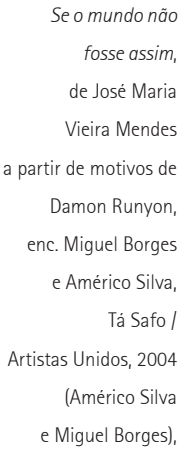

com benevolente penetração por Dostoievski. Numa segunda versão deste Crime e castigo, produzida posteriormente e apresentada com o título Lá ao fundo o rio, a acção e a narração ficaram condensadas. As estratégias e os recursos já utilizados foram afinados, com o objectivo de atingir uma maior coerência e uma menor dispersão dramática.

Morrer é um drama poético de enredo simples mas pouco linear, devolvido por contínuas elipses do discurso narrativo. 0 protagonista é condenado por uma doença incurável, a mulher quer morrer com ele, o homem deseja que ela viva. Mas o desespero e o amor desaparecem devagar - antes, de maneira imperceptível, a seguir, cada vez mais definida e definitivamente - deixando o espaço à resignação ao destino e à voracidade do egoísmo. 0 progredir da doença determina dois efeitos opostos nas personagens: a mulher acaba por aceitar a inevitabilidade da perda, reconciliandose com a morte e admitindo-a no seu quotidiano pela mediação da experiência do amado (por isso ela poderá continuar a viver); o homem ganha o horror do fim, quer agarrar-se à vida que the foge e não tolera a sobrevivência do seu universo à sua morte anunciada (por isso desejaria que a amada desaparecesse com ele). Não há amor obsessivo nem ódio numa tentativa de homicídio, apenas um sentido de inelutabilidade que é impossivel julgar. A parte mais interessante da peça, porém, é a intensidade poética com que é narrada, quase às avessas, pela protagonista. É ela que repercorre o fio da memória e reconstrói o passado para os espectadores, mas ao seu narrar corresponde a materialização das lembranças, ondas de imagens e diálogos que vão e vêm numa fluência por vezes dissonante, ou então mansas como uma ressaca.

Os traços distintivos dessas três adaptações, reformulados em novas doses e combinações, conotam também os dois textos redigidos e publicados recentemente,

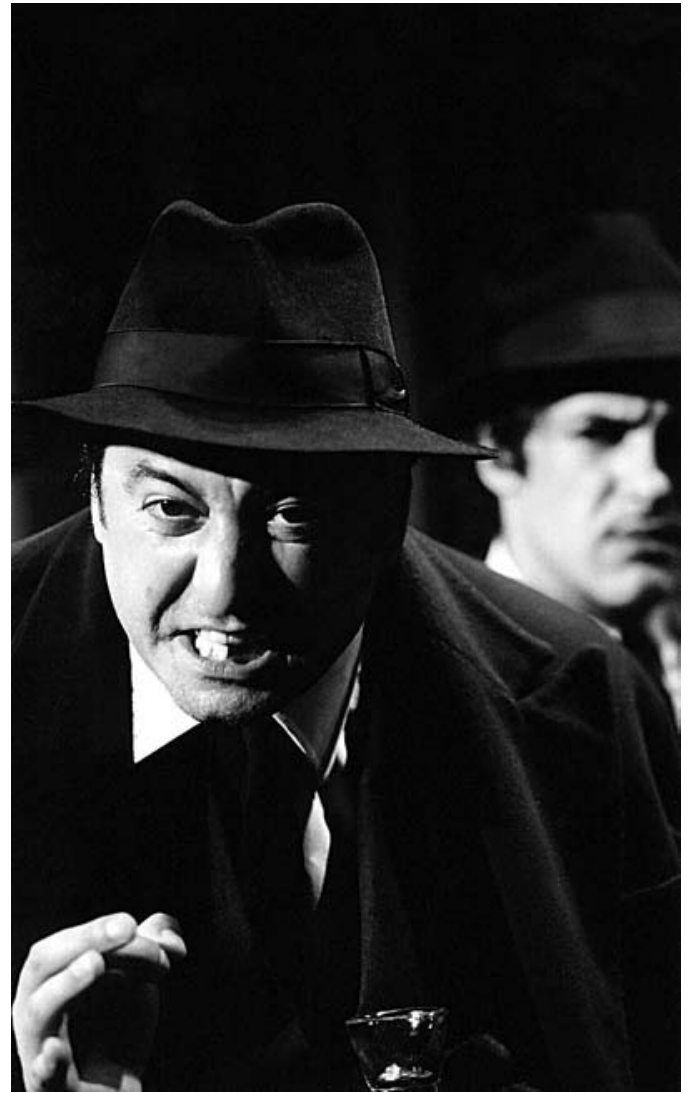

T1 (o primeiro original do autor) e Se o mundo não fosse assim (sobre motivos vindos de contos de Damon Runyon). $T 1$ retoma ambientes claustrofóbicos, habitados por seres frágeis ou perdidos num presente cinzento, perplexos e indefesos perante um futuro nebuloso, dotados porém duma ironia ausente nos seus antecessores. Se o mundo não fosse assim mescla elementos teatrais e cinematográficos, num enredo que se desenrola nos anos da "lei seca". As citações implícitas dos filmes hollywoodescos (desde os tempos do cinema mudo até certas películas de Woody Allen, passando pelas poses de Humphrey Bogart), encontram-se alternadas com uma homenagem submersa a Bertolt Brecht (desde as atmosferas de Na selva das cidades, até às técnicas do teatro épico, passando pelas construções de certas Lehrstücke).

Em T1, a peça que se pretende destacar deste conjunto de trabalhos de José Maria Vieira Mendes, a cena sugere 0 lugar onde se somam eventos, quase insignificantes e fragmentados, que não chegam a evoluir. No espaço fechado dum $T 1$, que na realidade condensa os quatro apartamentos distintos dos respectivos donos, o espectador é convidado a entrar em casa de Sara, Alberto, Chico e Vasco. A cada casa seu dono, cuja associação é permitida pelas falas das personagens e pelo auxílio da luminotecnia. Anagraficamente jovens e aproximadamente da mesma idade (vinte e tal anos as primeiras três, trinta e tal a última), elas têm porém uma idade que é dificil determinar pelas suas acções ou deixas. Percorrem (ou aguentam-se n)uma época da vida em que é preciso abandonar a adolescência e entrar na fase adulta, mas cada uma delas, à sua maneira, mostra as dificuldades e as contradições inscritas na aceitação dessa aventura. Sara luta pela sua autonomia, mas acaba por gerir relações em que o seu papel se limita à tradição de mulher / mãe apesar de não ter parido filhos. Alberto, velho / criança, 


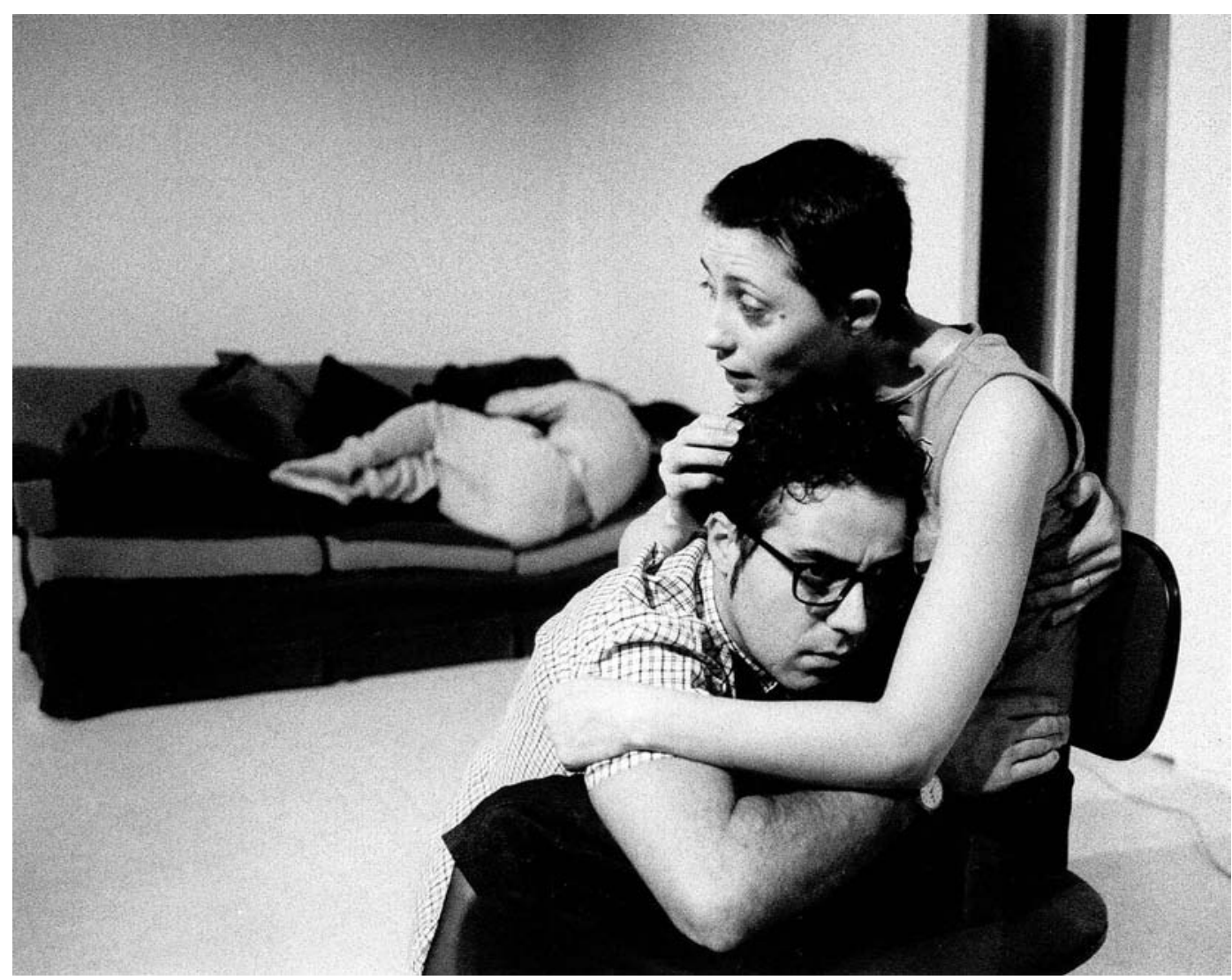

namorado de Sara, é escravo das suas idiossincrasias, um doente imaginário e dependente que torna a casa numa toca, candidatando-se ao abandono da namorada. Chico é o eterno adolescente / criança de esperteza duvidosa, que esconde na brincadeira o sofrimento pelo abandono do pai, escolhendo a imaginação e a fuga fácil dos pequenos expedientes ou da aposta nas raspadinhas. Vasco é um velho / criança quase enlouquecido pela dor do abandono de Laura, uma exnamorada presente na ausência e que Ihe devorou os sentimentos roendo-os até ao osso. E adolescentes em fuga são também os adultos que deveriam desempenhar a função de figuras referenciais desta juventude, mas que não passam de sombras disformes nos discursos dela: a mãe de Sara, decepcionada no amor por um body builder, pensa no suicídio; o pai de Chico, desaparecido sem deixar rasto, foi talvez atrás das saias de turno. Privados de modelos e valores a que se possam agarrar, as personagens tentam anestesiar os seus medos e inseguranças afogando-os nas cervejolas, acalmandoos nos cházinhos, adoçando-os na groselha ou exorcizandoos num sentido de humor pronunciado quase entredentes, nos breves momentos de leveza, entre umas e outras cenas que levam a nenhures. Nada progride. Tudo é vão. 0 pavor e a dor persistem, juntamente com uma (auto)agressividade quase autista. Há perguntas fundamentais, ainda à espera de resposta: como e quando se chega à idade adulta?

A eficácia cénica das peças acima referidas já foi testada e superou a prova do palco'. Aliás, os espectáculos resultaram da profícua colaboração do autor com os actores e as companhias. Este procedimento salienta a importância de conjugar os conteúdos da partitura textual com as especificidades da partitura cénica. Esses dados apontam e remetem para um dos fenómenos em que se articula a realidade teatral contemporânea: a ligação dos novos dramaturgos a uma ou mais companhias ou centros de produção. Assim, sem serem necessariamente dramaturgos residentes, essa realidade envolve os jovens José Maria Vieira Mendes, Jacinto Lucas Pires, Miguel Castro Caldas e Pedro Eiras, entre outros, mas também, e talvez com menor assiduidade, os mais experientes Armando Nascimento Rosa, Abel Neves, Luis Carlos Patraquim, Luisa Costa Gomes e Jaime Rocha. Se é raro que os dramaturgos tenham a sua própria companhia (Carlos J. Pessoa é a excepção que confirma a regra), pelo menos de momento fica-se com a impressão de estarem menos exilados do palco do que as gerações que os antecederam (uma "velha guarda" composta por poucos resistentes e vários desistentes). Para bem do teatro, os textos procuram, e por vezes conseguem, aproximar-se das cenas. Em Portugal e em português.
$T 1_{1}$

de José Maria Vieira Mendes, enc. Jorge Silva Melo, Artistas Unidos, 2004 (Pedro Carraca, Joana Bárcia e Miguel Borges), fot. Jorge Gonçalves.

\section{Dois homens, um}

projecto de Luis Gaspar e José Maria Vieira Mendes, foi estreado em 1998

durante o seminário "Sem Deus Nem Chefe 1", uma iniciativa dos Artistas Unidos. Crime e castigo, uma co-produção AU / APA / EBAHL, foi apresentado no Teatro Taborda em 1999. Morrer, concebido com os actores Luís Gaspar e Catarina Requeijo, subiu à cena na Sala Estúdio do Teatro da Trindade em 1999. Lá ao fundo o rio, levado à cena pelos AU numa encenação de Manuel Wiborg, estreou no Teatro da Malaposta em 2000. $T 1$, produzido ainda pelos AU, estreou no Taborda na Primavera de 2004, numa encenação de Jorge Silva Melo assistido por João Meireles e Américo Silva (o texto foi levado à cena também no Brasil e, sob a forma de mise en espace, foi apresentado no Piccolo Teatro di Milano). Se o mundo não fosse assim, um trabalho de Miguel Borges e Américo Silva produzido por Tá Safo / AU, também apresentado no Taborda em 2004. 